\title{
Paraxial Nodal Expression Reveals a Novel Conserved Structure of the Left-Right Organizer in Four Mammalian Species
}

\author{
Silke S. Schröder ${ }^{a}$ Nikoloz Tsikolia ${ }^{a}$ Annette Weizbauer ${ }^{a}$ Isabelle Hue ${ }^{b}$ \\ Christoph Viebahn ${ }^{a}$ \\ anstitute of Anatomy and Embryology, University Medical Centre Göttingen, Göttingen, Germany; \\ bINRA, UMR1 198 Biologie du Développement et Reproduction, Jouy-en-Josas, France
}

\section{Key Words}

Development · Left-right patterning · Gastrulation ·

Notochord $\cdot$ Nodal $\cdot$ Ciliary flow $\cdot$ Amniote evolution .

Mammalia

\begin{abstract}
Nodal activity in the left lateral plate mesoderm is a conserved sign of irreversible left-right asymmetry at early somite stages of the vertebrate embryo. An earlier, paraxial nodal domain accompanies the emergence and initial extension of the notochord and is either left-sided, as in the chick and pig, or symmetrical, as in the mouse and rabbit; intriguingly, this interspecific dichotomy is mirrored by divergent morphological features of the posterior notochord (also known as the left-right organizer), which is ventrally exposed to the yolk sac cavity and carries motile cilia in the latter 2 species only. By introducing the cattle embryo as a new model organism for early left-right patterning, we present data to establish 2 groups of mammals characterized by both the morphology of the left-right organizer and the dynamics of paraxial nodal expression: presence and absence of a ventrally open surface of the early (plate-like) posterior notochord correlates with a symmetrical (in mice and rab-
\end{abstract}

bits) versus an asymmetrical (in pigs and cattle) paraxial nodal expression domain next to the notochordal plate. Highresolution histological analysis reveals that the latter domain defines in all 4 mammals a novel 'parachordal' axial mesoderm compartment, the topography of which changes according to the specific regression of the similarly novel subchordal mesoderm during the initial phases of notochord development. In conclusion, the mammalian axial mesoderm compartment (1) shares critical conserved features despite the marked differences in early notochord morphology and early left-right patterning and (2) provides a dynamic topographical framework for nodal activity as part of the mammalian left-right organizer. @ 2016 The Author(s)

Published by S. Karger AG, Basel

\begin{tabular}{ll}
\hline Abbreviations used in this paper \\
\hline LPM & lateral plate mesoderm \\
LR & left-right \\
LRO & left-right organizer \\
PBS & phosphate-buffered saline \\
PCP & planar cell polarity \\
PNC & posterior notochord \\
SELI & self-enhancement and lateral inhibition \\
\hline
\end{tabular}

\begin{tabular}{|c|c|c|}
\hline KARGER & $\begin{array}{l}\text { (๐) } 2016 \text { S. Karger AG, Basel } \\
1422-6405 / 16 / 2012-0077 \$ 39.50 / 0\end{array}$ & $\begin{array}{l}\text { Karger } \\
\text { Open access }\end{array}$ \\
\hline $\begin{array}{l}\text { E-Mail karger@karger.com } \\
\text { www.karger.com/cto }\end{array}$ & $\begin{array}{l}\text { This article is licensed under the Creative } \\
\text { NonCommercial-NoDerivatives } 4.0 \text { IItern } \\
\text { NC-ND) (http://www.karger.com/servic } \\
\text { Usage and distribution for commercial pur } \\
\text { tribution of modified material requires wri }\end{array}$ & $\begin{array}{l}\text { Commons Attribution- } \\
\text { ational License (CC BY- } \\
\text { es/OpenAccessicense). } \\
\text { rposes as well as any dis- } \\
\text { tten permission. }\end{array}$ \\
\hline
\end{tabular}

Christoph Viebahn

Institute of Anatomy and Embryology, University Medical Centre Göttingen Kreuzbergring 36

DE-37075 Göttingen (Germany)

E-Mail christoph.viebahn@ medizin.uni-goettingen.de 


\section{Introduction}

The $\beta$-type transforming growth factor nodal shows a highly conserved expression in the lateral plate mesoderm (LPM) at the 4-somite stage in both birds [Levin et al., 1995] and mammals [Lowe et al., 1996; Blum et al., 2007] and at higher-somite stages in Xenopus and zebrafish [Rebagliati et al., 1998; Schweickert et al., 2007]. Once nodal mRNA expression appears in the LPM on the left side, the molecular left-right (LR) asymmetry of the body plan is fixed. In mammals, there appears to be a labile phase of symmetry breaking at the pre- or early-somite stage, i.e. preceding the emergence of the LPM nodal expression domain, which is marked by paraxial nodal expression at the level of the posterior third of the emerging notochord (PNC): in the mouse this domain lies in the so-called crown cells [McGrath et al., 2003] and in the rabbit it lies in equivalent, as yet less well-defined cells [Feistel and Blum, 2006]. Initially, the paraxial domain is bilaterally symmetrical in the mouse and rabbit, but in the pig it is restricted to the left side [Gros et al., 2009] as in the chick [Levin et al., 1995; Tsikolia et al., 2012].

Motile cilia on the PNC are thought to be necessary for molecular LR patterning in species such as the frog, the rabbit, and the mouse [Okada et al., 1999; Feistel and Blum, 2006; Blum et al., 2007; Schweickert et al., 2007] as these cilia have been proven to produce a left-sided 'ciliary flow' of yolk sac fluid in the immediate vicinity of the ventral PNC surface. For this reason, the ciliated PNC has also been termed the LR organizer (LRO) [Basu and Brueckner, 2008]. Genetic analyses in humans and mice have given this concept strong support in that genetically defined ciliary defects are closely related to irregular LR patterning as in, for example, Kartagener's syndrome [Olbrich et al., 2002; Loges et al., 2008; Leigh et al., 2009; Merveille et al., 2011]. An intriguing refinement of the ciliary flow model followed the discovery that 2 types of monocilia, i.e. motile and immotile cilia were (1) located centrally and peripherally, respectively, on the ventral PNC surface, and (2) required to emit or receive signals that initiate molecular LR asymmetry [McGrath et al., 2003; Boskovski et al., 2013]; ciliary flow is thus sensed by immotile cilia in a $\mathrm{Ca}^{++}$-dependent process which requires polycystin-2 [Yoshiba et al., 2012] and leads to leftsided inhibition of the nodal repressor cerl-2 [Nakamura et al., 2012] or its Xenopus homologue Coco [Schweickert et al., 2010]. Further propagation of the molecular asymmetry is suggested to be mediated by 'self-enhancement and lateral inhibition' (SELI model) involving both nodal and lefty activity [Nakamura et al., 2006]. A primary ne- cessity for an efficient asymmetrical flow is the posterior positioning of cilia on notochord cells, which has been shown to be dependent on the planar cell polarity (PCP) pathway [Song et al., 2010], and notochordal ciliogenesis per se requires activity of transcription factor Foxj1 [Stubbs et al., 2008; for a review, see Blum et al., 2014].

However, the ciliary mechanism is precluded to be universal for all vertebrates as some species such as the pig or the chick have neither a free ventral PNC surface nor notochordal cilia at relevant stages of embryonic development [Jurand, 1974; Bancroft and Bellairs, 1976; Männer, 2001; Gros et al., 2009]. Instead, chick embryos show an asymmetric morphology of the early node [Dathe et al., 2002] and a substantial PNC consisting of hypoblast and a newly discovered layer of axial mesoderm, i.e. the subchordal mesoderm [Tsikolia et al., 2012]. An asymmetrical node is also known from the porcine embryo [Gros et al., 2009], but whether there is a subchordal mesoderm domain covering the notochord in addition to the hypoblast in the pig, too, has not yet been described. Interestingly, a covered ventral PNC surface and the absence of motile cilia correlate with initial asymmetry in the paraxial nodal domain on the one hand (i.e. in the pig and the chick), and a free ventral surface equipped with motile cilia and ciliary flow correlates with a symmetrical paraxial nodal domain on the other (i.e. in the mouse and the rabbit).

To test the likely hypothesis that a conserved scenario of LR symmetry breaking exists in mammals (and possibly amniotes) in general, we carried out a comparative search for the topography and expression dynamics of nodal at early notochord stages in 4 mammalian model organisms: mice, rabbits, pigs, and cattle. Cattle were included in this study because there is some indication [Haldiman and Gier, 1981] that the notochord is covered temporarily as in the pig [Gros et al., 2009], but this has yet to be analyzed systematically. Using high-resolution histology, we sought to define - at the level of individual cells - the nodal expression domains in the vicinity of the PNC and intended to correlate them with (1) known divergent morphological features of the notochord and (2) the topography of the subchordal mesoderm, i.e. the novel axial mesoderm compartment. The results on the morphology of the LRO and on the initial nodal expression corroborate the existence of 2 mammalian groups with regard to early LR patterning. Despite this divergence, paraxial nodal-expressing cells appear to belong to a homologous compartment lateral to the notochord in both groups, and their positioning closely correlates with the specific degree of regression of the subchordal mesoderm. Following the comparative analysis by Hayek
78

Cells Tissues Organs 2015-16;201:77-87 DOI: $10.1159 / 000440951$
Schröder/Tsikolia/Weizbauer/Hue/ Viebahn 
[1931], we suggest terming these paraxial cells 'parachordal cells' and present them as a central common element during symmetry breaking and early LR patterning in amniotes.

\section{Materials and Methods}

\section{Embryos}

The embryos investigated in this study were from rabbits (New Zealand white, Oryctolagus cuniculus) obtained from Lammers (Euskirchen, Germany) and Charles-Rivers (Geislingen, Germany) or pigs (Sus scrofa domesticus) obtained from the Faculty of Agricultural Sciences (Göttingen, Germany), cattle (Bos primigenius taurus) obtained from INRA, UMR1198 Biologie du Développement et Reproduction (Jouy-en-Josas, France), and mice [Mus musculus, C57BL/6 (BL6) strain origin] obtained from the ZTE of the University Medical Centre Göttingen. Uteri of pigs, rabbits and mice were removed from euthanized animals as a whole and transferred into warm $\left(37^{\circ} \mathrm{C}\right)$ phosphate-buffered saline (PBS) for blastocyst flushing (pig embryos, early-stage rabbit embryos) or dissection (olderstage rabbit embryos, mouse embryos) in PBS at room temperature as described before (Blum et al., 2007; Hassoun et al., 2009). Cattle embryos were collected transcervically without the need for euthanasia as described by Richard et al. [2014]. After dissection, the embryos to be used for in-situ hybridization analysis were incubated in $4 \%$ paraformaldehyde for $1 \mathrm{~h}$, washed several times in PBS followed by ascending alcohol concentrations for dehydration, and stored at $-20^{\circ} \mathrm{C}$ in $100 \%$ ethanol. Embryos to be used for high-resolution light microscopy on semithin sections were fixed in $1.5 \%$ paraformaldehyde and $1.5 \%$ glutaraldehyde in phosphate buffer, postfixed in $1 \% \mathrm{OsO}_{4}$ in phosphate buffer as described by Schwartz et al. [1984].

\section{Staging}

Staging in rabbits, pigs, and cattle was geared to the morphological criteria implemented by Hamburger and Hamilton [1951] for the chick. Stage 4 is defined by the appearing node [Stern, 2004] and a maximally extended primitive streak. Stage 5 shows a cellular density along the anterior-posterior axis in the midline anterior to the node, i.e. the extending notochord which exceeds the primitive streak in length at the beginning of stage 6 . The appearance of the first 3 pairs of somites marks stage 7 . For the mouse embryo, the staging system of Theiler [1972] was used, Theiler stage 11 taken to be equivalent to stages 5 and 6 , Theiler stage 12 equivalent to stage 7 .

\section{PCR Cloning and in situ Hybridization}

The bovine nodal probe (HQ424159) was isolated from bovine D15 embryonic discs [Maruotti et al., 2012]. In situ hybridization was carried out for each gene and stage described here at least in triplicate and following a standard protocol [Weisheit et al., 2002] as follows: embryos stored at $-20^{\circ} \mathrm{C}$ were transferred to nylon baskets for rehydration and treatment with Proteinase K [Tsikolia et al., 2012] for either $10 \mathrm{~min}$ (stages 4 and 5) or $15 \mathrm{~min}$ (stage 6-8), followed by a fixation step (20 min in $0.2 \%$ glutaraldehyde/PBS with Tween). After $1 \mathrm{~h}$ of prehybridization in hybridization buffer [ $50 \%$ formamide, $1.4 \times$ saline sodium citrate buffer $(\mathrm{pH} 4.5), 0.5$ $\mathrm{mM}$ ethylenediaminetetra-acetic acid, $50 \mu \mathrm{g} / \mathrm{l}$ t-RNA, $0.2 \%$ Tween
20, 0.5\% CHAPS, and $50 \mathrm{mg} / \mathrm{ml}$ heparin (Sigma, München, Germany)] preheated to $70^{\circ} \mathrm{C}$, the hybridization step was carried out overnight in hybridization buffer at $70^{\circ} \mathrm{C}$ with $1 \mu \mathrm{g} / \mathrm{ml}$ digoxigenin-labeled cDNA denatured at $95^{\circ} \mathrm{C}$. To prevent evaporation of the warm hybridization buffer, these steps were carried out in sterile screw-top PVC tubes (Bibby-Sterilin, Staffordshire, UK). After at least $12 \mathrm{~h}$ of incubation, the embryos were washed in hybridization buffer and maleic acid buffer with Tween [100 mM maleic acid, 150 $\mathrm{mm} \mathrm{NaCl}, 0.1 \%$ Tween 20 (pH 7.5)] to remove surplus cDNA. The next incubation step was carried out with maleic acid buffer with Tween to which 2\% Roche blocking reagent and 20\% heat-inactivated goat serum were consecutively added. The color reaction of the anti-digoxigenin antibody conjugated to alkaline phosphatase with BM purple substrate (both from Roche, Mannheim, Germany) was carried out at room temperature in the dark in substratefilled petri dishes for several days. For whole-mount photography, embryos were embedded in Mowiol ${ }^{\circledR}$ (Carl Roth, Karlsruhe, Germany) under a cover glass on a microscope slide.

\section{Morphological Analysis}

For high-resolution light microscopy, $\mathrm{OsO}_{4}$-fixed embryos were embedded in Araldite ${ }^{\circledR}$ (Serva, Heidelberg, Germany) [Schwartz et al., 1984] and serially sectioned at $1 \mu \mathrm{m}$ in the transverse or the sagittal plane. In situ hybridized embryos were embedded in Technovit $8010^{\circledR}$ (Heraeus Kulzer, Werheim, Germany) and serially sectioned at $5 \mu \mathrm{m}$. Photographs were taken of dorsal views of each embedded embryo prior to sectioning, and semithin sections $(1 \mu \mathrm{m})$ were stained with $1 \%$ toluidine blue, while Technovit sections were photographed unstained using differential interference contrast. Serial sections were correlated with dorsal views of the same embryo to allocate the critical structures seen in dorsal views to specific section numbers and vice versa.

\section{Specimen Numbers}

In situ hybridization for nodal expression was carried out on 3 mouse embryos (all Theiler stage 12), 29 rabbit embryos (of those, 6 embryos were stage 5, 8 were stage 6 and 3 were stage 7), 71 pig embryos (of those, 8 embryos were stage 4 and 30 embryos were stage 5), and 12 bovine embryos (of those, 6 embryos were stage 5). For high-resolution light microscopy, we investigated 9 mouse embryos, 17 rabbit embryos, 20 pig embryos, and 6 bovine embryos.

\section{Results}

\section{Nodal Expression}

The expression dynamics of nodal mRNA as the earliest marker of LR symmetry breaking was studied in pigs and cattle and compared to expression dynamics in mice and rabbits using identical in situ hybridization protocols. Special attention was given to the stages immediately following the initiation of notochord formation, which is characterized by the sudden disappearance of the strong nodal expression domain in the primitive streak [Collignon et al., 1996].

Paramedian nodal expression in the mouse (fig. 1a) was first observed at the beginning of somitogenesis in 2 sym- 
Fig. 1. Whole-mount views of nodal mRNA expression domains during formation of the early (plate-like) notochord in mouse (a), rabbit (b, c), pig (d-f), and cattle (g-i) embryos. Porcine embryos show the node at the caudal part of the embryo, while in bovine embryos the node (and nodal expression) is located in the center of the embryo. Asterisks indicate somites and arrowheads indicate the position of the node. Lines mark the position of sections (taken from different specimens in the case of mice and cattle) shown in figure 2. 1 = Left; $\mathrm{r}=$ right; $\mathrm{a}=$ anterior; $\mathrm{p}=$ posterior. Scale bars $=0.05 \mathrm{~mm}$ for mice and rabbits at stage $6(\mathbf{a}, \mathbf{b}), 0.1 \mathrm{~mm}$ for rabbits at stage 7 (c), $0.16 \mathrm{~mm}$ for pigs and cattle at stage $5 / 6$ (d, g), and $0.176 \mathrm{~mm}$ for pigs and cattle at stages 7 and $8(\mathbf{e}, \mathbf{f}, \mathbf{h}, \mathbf{i})$.
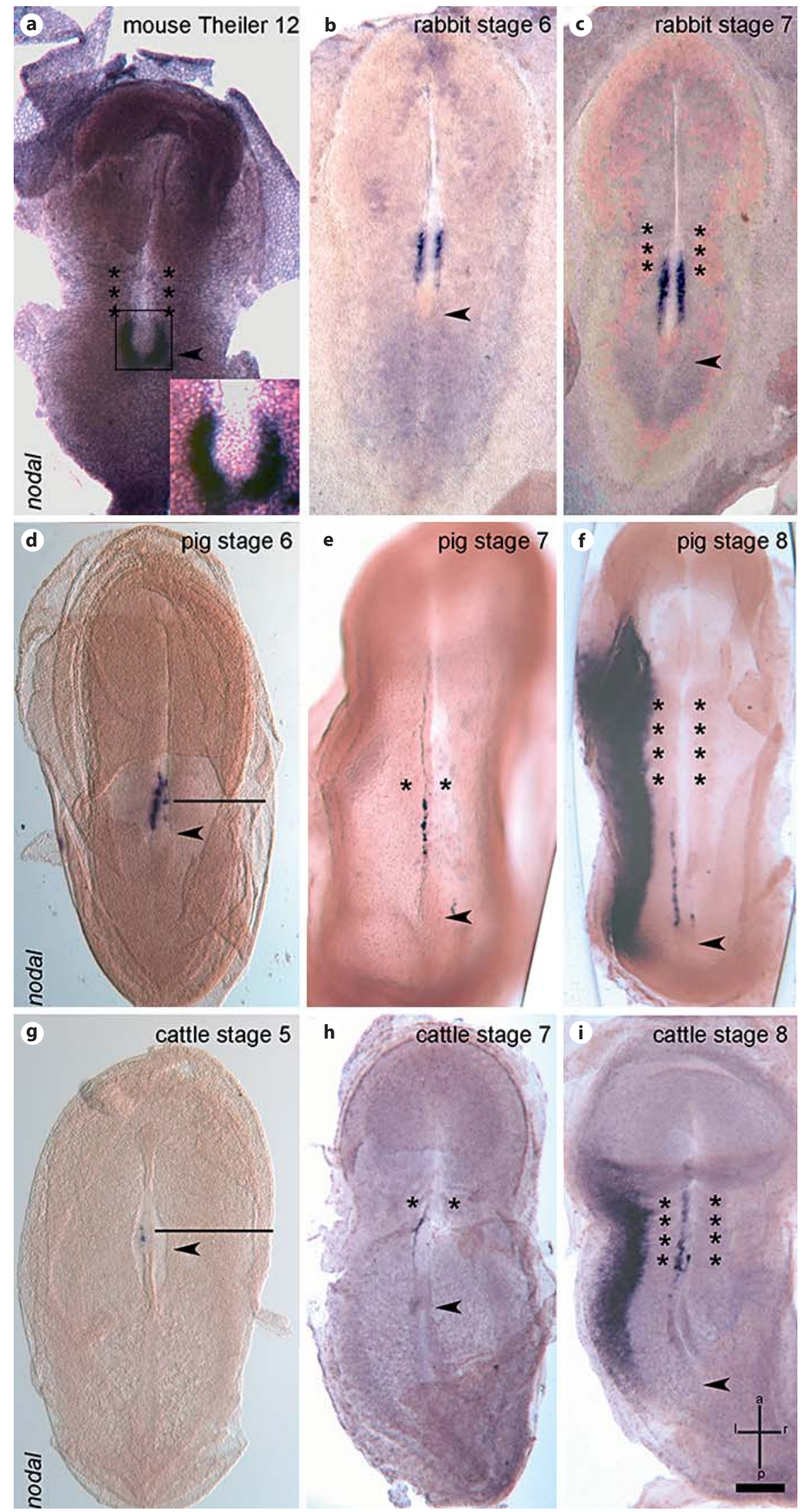

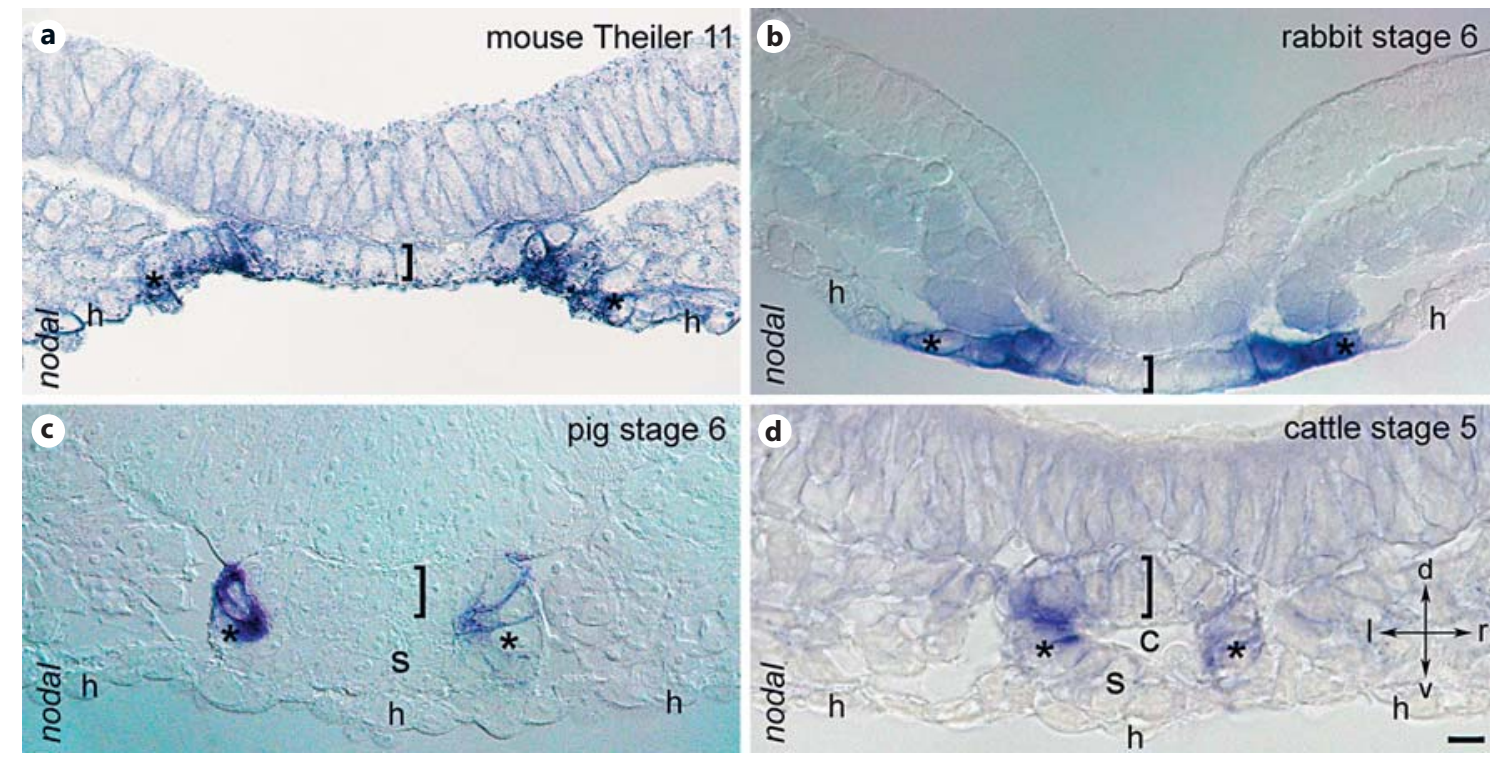

Fig. 2. Transverse sections from embryos subjected to in situ hybridization showing nodal expression in lateral PNC cells in all 4 species studied. Asterisks mark the lateral boundary of the notochordal plate, and brackets mark the height of the notochordal plate. $\mathrm{h}=$ Hypoblast; $\mathrm{s}=$ subchordal mesoderm; $\mathrm{c}=$ notochordal $\mathrm{canal} ; \mathrm{l}=\mathrm{left} ; \mathrm{r}=$ right; $\mathrm{d}=$ dorsal; $\mathrm{v}=$ ventral. Scale bar $=0.01 \mathrm{~mm}$.

metrical stripes converging in the midline at the level of the node (thus coinciding with the so-called crown cells) [Bellomo et al. 1996], which is in accordance with published data [Zhou et al., 1993; Collignon et al., 1996; Shiratori and Hamada, 2006; Blum et al., 2007]. In the rabbit, paramedian nodal expression was first seen at stage 6 in 2 symmetrically arranged longitudinal paraxial domains (fig. 1b) which were equally strong and symmetrical also at stage 7 (fig. 1c) and stage 8 (4 somites), when nodal is additionally expressed in the left LPM [Blum et al., 2007]. In porcine and bovine embryos, paraxial nodal expression was seen from an advanced stage 5 onwards (fig. $1 \mathrm{~d}-\mathrm{f}$, $\mathrm{g}-\mathrm{i}$ ), but the expression levels showed a distinct LR asymmetry in which the nodal expression domain was more intense and larger on the left than on the right (fig. 1d, 2c, d). Some embryos exhibited an expression domain on the left only (fig. 1e, h). The expression domains became stronger but continued to be asymmetrical through stage 7 (fig. 1e, h) until nodal expression started in the LPM at the 4 -somite stage (stage 8; fig. 1f, i). In addition to the intensity, the length of the nodal expression domain on the left increased between stages 5 and 8 .

Interestingly, the paraxial nodal expression domain is located at about the same level as the first somite pair which emerges at stage 7 in a similar manner in both pigs and cattle; at stage 8 , however, the paraxial nodal domain lies distinctly caudal to the last formed somite pair in the pig (fig. 1f), whereas in the bovine embryo the paraxial nodal domain continues to lie at the level of caudal-most somite pair (fig. 1i). As a consequence, the topographical relationship between the paraxial and LPM domains contrasts markedly between these two species: the paraxial domain lies next to the posterior third of the LPM domain in pigs (fig. 1f), but it lies near the center of the LPM domain in cattle (fig. 1i).

Histological analysis of $5-\mu \mathrm{m}$ sections of the symmetrical paraxial nodal expression domains in the mouse and the rabbit confirmed the known cellular distribution of nodal mRNA to cells immediately adjacent to the PNC [mouse (fig. 2a), Zhou et al., 1993; Collignon et al., 1996; Shiratori and Hamada, 2006; rabbit (fig. 2b), Blum et al., 2007]. Comparing this position of nodal-expressing cells lateral to the PNC in mice and rabbits with the situation in pigs and cattle (fig. 2c, d), a novel structural feature of the early mammalian PNC becomes apparent: in pigs and cattle, nodal-expressing cells form a lateral epitheliumlike compartment where the medial-most nodal mRNAcontaining cell is in direct lateral contact with the epithelial cells of the PNC, but - due to the tilted position of the nodal domain in these two species - the lateral-most nodal-containing cells point with their lateral cell membrane ventrally and thereby touch the mesenchymally organized compartment ventral to the PNC, recently defined in the chick as subchordal mesoderm [Tsikolia et al., 
Fig. 3. Notochord morphology in different mammalian embryos at stage 5 or 6 as seen in median sagittal sections. The notochordal plate can be recognized as an epithelium stretched out longitudinally ventral to the neural ectoderm (presumptive floor plate) in all species shown. In rabbits and mice, the ventral (apical) notochord surface (which is equipped with rotating monocilia) communicates freely with the yolk sac cavity below in rabbits and mice, but it is covered by (squamous) endoderm (or hypoblast) epithelium in cattle and pigs. The posterior part of the notochordal plate, i.e. the PNC, is covered - to different degrees in these 4 species - by the subchordal mesoderm, which is continuous posteriorly with the primitive streak. Colored insets highlight the relative position of cells anterior to the chordoneural hinge (vertical arrow) with respect to the ectoderm, the notochord, the subchordal mesoderm, and the hypoblast. e = Ectoderm (red in insets); s = subchordal mesoderm (yellow); $\mathrm{h}=$ hypoblast (green); $\mathrm{c}=$ notochordal canal. Brackets mark the height of the notochordal plate (blue). Arrows mark the chordoneural hinge as identified by investigation of neighboring semithin sections. " Artificial space between the ectoderm and the notochord. $\mathrm{d}=$ Dorsal; $\mathrm{v}=$ ventral; $\mathrm{a}=$ anterior; $\mathrm{p}=$ posterior. Scale bar $=0.01 \mathrm{~mm}$.

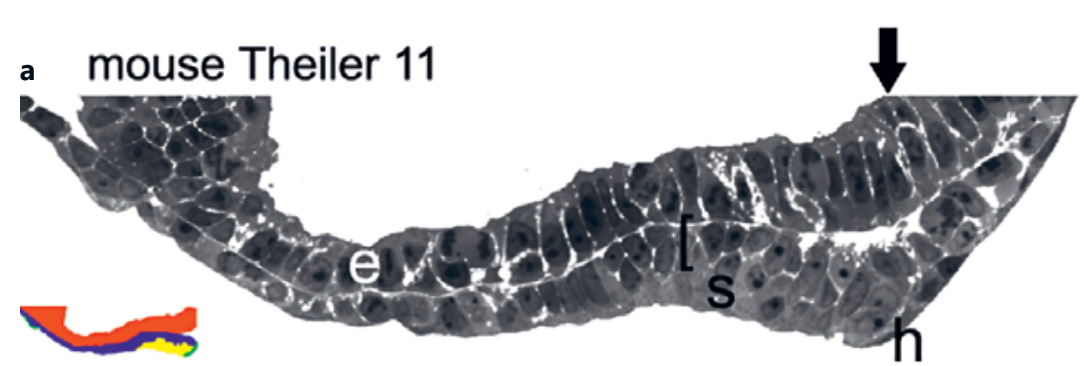

b rabbit stage 6
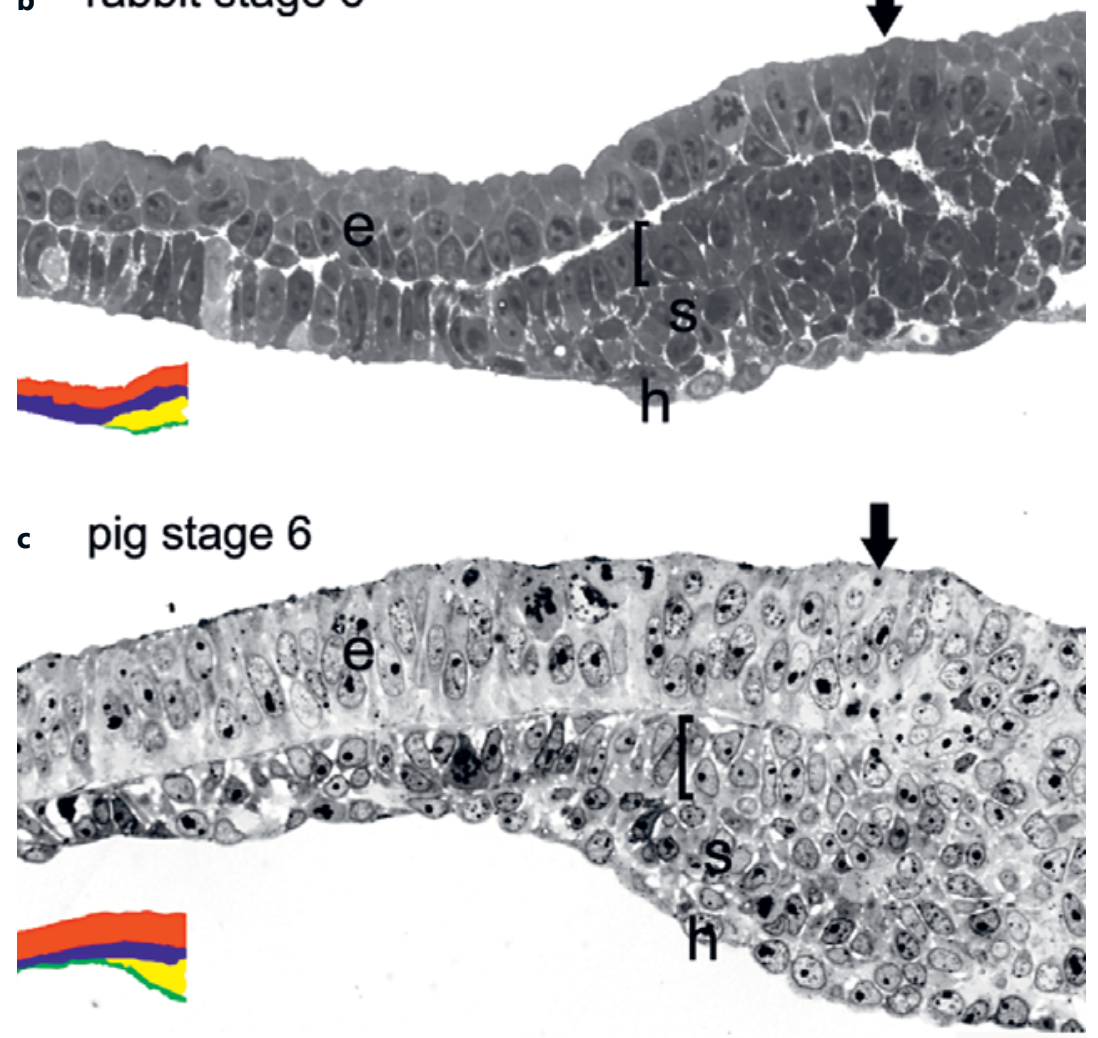

\section{d cattle stage 5}

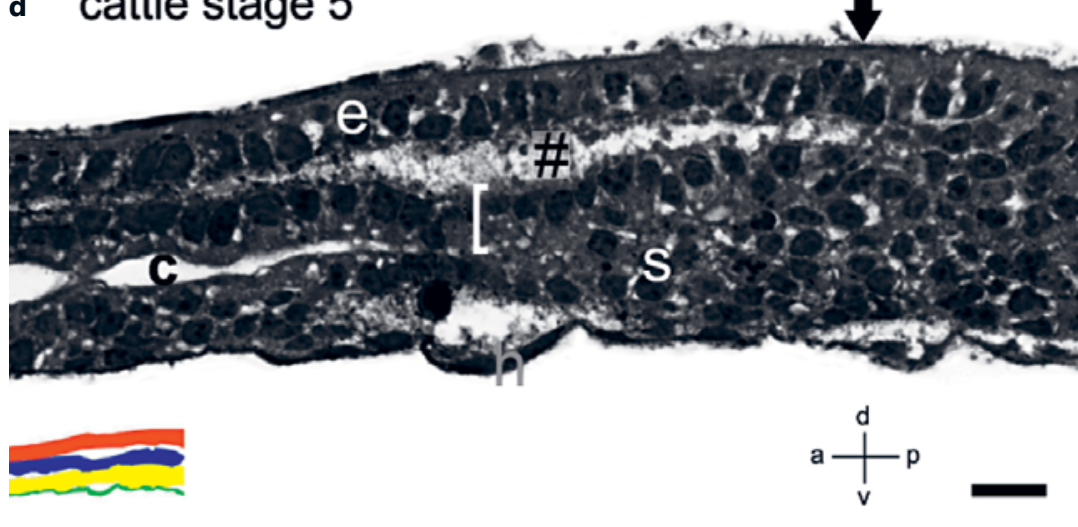


2012]. In rabbits and mice the nodal-expressing domain is also in direct contact (medially) with the epithelial PNC, but laterally it contacts the hypoblast or visceral endoderm because in these species the notochord is inserted into the lower layer (hypoblast or visceral endoderm, respectively) soon after its emergence from the node [Sulik et al., 1994; Blum et al., 2007].

Variability of the Mammalian Subchordal Mesoderm

The variability of the paraxial nodal domain in the transverse plane observed in the 4 mammalian species analyzed in this study is directly related to the presence or absence of the subchordal mesoderm, which has been formally described as a mesenchyme-like compartment of the early axial mesoderm so far in the chick only [Tsikolia et al., 2012]. Therefore, the following high-resolution light-microscopy analysis was carried out on serial sagittal semithin $(1-\mu \mathrm{m})$ sections through the early (plate-like) notochord. These sections show in all 4 species (fig. 3a-d) that the basal aspect of the emerging notochordal plate epithelium lies back-to-back with the basal side of the high-columnar, pseudostratified epithelial layer of neuroectoderm (the future floor plate), which is especially high in porcine embryos (fig. 3c). Between the neuroectoderm and the notochordal plate, a distinct line of separation can be seen under a light microscope and is a bona fide representation of the neuroectoderm basement membrane. This basement membrane ends immediately anterior to the primitive node, which is continuous anteriorly with both the neuroectoderm and the notochordal plate, and thereby indicates the position of the future median hinge point of the neural plate in the transverse plane [Smith and Schoenwolf, 1989] and the chordoneural hinge in the sagittal plane [Cambray and Wilson, 2002]. As known from previous studies in the mouse, the rabbit [Blum et al., 2007], and the pig [Gros et al., 2009], the apical surface of the notochordal plate is exposed to the yolk sac cavity in the mouse and the rabbit (fig. $3 a, b$ ), but it is covered by the thin hypoblast epithelium in the pig (fig. 3c). In cattle, too, the notochordal plate is covered by hypoblast as seen in the bovine specimens available for this part of the study and displaying a short notochordal plate typical for stage 5 (fig. 3d), while already at stage 6 the elongating notochord is gradually uncovered from hypoblast [Haldiman and Gier, 1981] as observed in the mouse and the rabbit. Indeed, transverse Technovit sections at stage 5 also showed a continuous hypoblast covering on the ventral side of the posterior axial mesoderm (fig. 2d).

Paraxial Nodal Expression and the LRO
Independently of the presence or absence of a hypoblast covering, all 4 species investigated here show a distinct population of cells representing the subchordal mesoderm ventral to the epithelium-like notochordal plate and immediately anterior to the primitive node: in contrast to the overlying notochordal plate, the subchordal mesoderm cells have a mesenchymal appearance and are in direct contact with the epithelial cells of the notochordal plate at their dorsal side, as well as with the ventral cells of the primitive node caudally. In its caudal part, the subchordal mesoderm is covered by hypoblast in all 4 species, while anteriorly it is either, in mice and rabbits (fig. 3a, b), exposed to the yolk sac cavity (as is the notochordal plate) or, in pigs and cattle, covered (again similar to the notochordal plate) by hypoblast (fig. 3c, d). The subchordal mesoderm thus forms a common feature of the species investigated here, but differences between species exist in terms of shape and the dynamics of its shape changes during stages 5 and 6: in rabbits and mice, the subchordal mesoderm 'measures' $5-10$ cells in anterior-posterior length and is 1-2 cells thick along the dorsal-ventral axis (fig. 3a, b); it is only present during stages 5 and 6 and is therefore difficult to detect, especially in the mouse egg cylinder with its marked dorsal bending of the node epiblast. In pigs and cattle, in contrast, the subchordal mesoderm is approximately twice as high (fig. $3 \mathrm{c}, \mathrm{d}$ ) compared to the notochordal plate and remains present well into stage 6 .

\section{Discussion}

The asymmetrical, left-sided nodal expression in the LPM of all 4 mammals analyzed in this study corroborates the well-known conserved feature of a definitively committed LR axis at early somite stages in amniote embryos. The paraxial nodal domains, which are symmetrical in mice and rabbits but are initially asymmetrical in pigs and cattle, further support the interspecific dichotomy of the notochordal plate being covered ventrally in cattle and pigs but exposed to the yolk sac cavity in mice and rabbits. Unexpectedly, comparative histological analysis of gene expression revealed that in all 4 species, too, the paramedian nodal domain is part of a parachordal tissue connecting the (potentially cilia-bearing) notochord with the subchordal mesoderm. In their topographical arrangement they resemble the parachordal cells defined by Hayek [1931], and because of the nodal expression in some of them and their intimate contact with the LRO we now suggest that they may have a functional significance for LR

Cells Tissues Organs 2015-16;201:77-87 DOI: $10.1159 / 000440951$ 
patterning. The following discussion deals with the subchordal mesoderm first because of its topographical influence on the configuration of the nodal domain.

\section{Axial Mesoderm and LR Patterning}

The specific structural differences in the vicinity of the notochord, which is the central element of the axial mesoderm, were particularly apparent in sagittal sections (fig. 3). Based on our morphological analysis, as well as on our in situ hybridization of nodal, we can distinguish between species with an initially symmetric nodal expression and a ventrally open PNC and species with an initially asymmetric nodal expression and a notochord ventrally covered by subchordal mesoderm and endoderm (or hypoblast). Interestingly, subchordal mesoderm is not completely lacking in mice and rabbits but is merely reduced in its anterior-posterior extension by the early insertion of the PNC into the hypoblast layer. The speedy development of mice and rabbits (6-7 days) until the emergence of the PNC (as compared to the 'slow' speed in pigs and cattle, i.e. 12-13 days, for the same developmental process) may explain this early 'disappearance' of the subchordal mesoderm. The intense ventral buckling of the embryo into the egg cylinder shape may be an additional factor in the mouse [and rat, Bellomo et al., 1996] for the early size reduction of the subchordal remnant (fig. 3a), which is even smaller than that in the rabbit (fig. 3b). Although one cannot exclude the possibility that (short) monocilia may be present on PNC cells in pigs and cattle, the lack of a specific topographical arrangement like an open PNC [or Kupffer's vesicle as in the fish, Essner et al., 2005], as well as the incipient asymmetry of nodal expression (see below), makes cilia-dependent flow in these species unnecessary for LR symmetry breaking and thus an unlikely causal factor in LR patterning, similar to the situation seen in the chick [Tsikolia et al., 2012]. However, it will be most interesting now to find out whether ultrastructural studies or immunohistochemical detection of ciliary proteins, e.g. acetylated tubulin, can reveal ciliary components on the 'virtual' apical surface of the PNC represented by the border between the PNC and the subchordal mesoderm. Such ciliary remnants may well harbor, or at least be signs of, motile or sensory molecular components known to be involved in LR patterning [McGrath et al., 2003]. To further test the divergence of early LR patterning, it would be crucial to study the expression pattern of nodal antagonist dand5 and the ciliary master gene foxj 1 in the LRO of pigs and cattle.

\section{Axial Mesoderm and the Parachordal Nodal}

\section{Expression Domain}

The paraxial nodal domain of the mouse, which connects nodal-expressing parachordal cells with the ventral node region, indicates a structural continuity of the subchordal mesoderm with parachordal epithelial cells and therefore functional involvement of the subchordal mesoderm in the generation of this parachordal domain. However, whether the subchordal mesoderm of amniotes indeed contributes to the formation of the parachordal nodal domain remains to be clarified. Furthermore, nodal expression in cattle and pigs is confined to the axial mesoderm. This is worthy of mention in connection with endoderm generation [Lewis and Tam, 2006] because the topographical origin of definitive endoderm from node or streak (or both) is still unresolved: assuming homology of the paraxial nodal domains in the 4 mammals studied here, we suggest that nodal-expressing parachordal cells in the rabbit and the mouse are part of the LRO and do not belong to endoderm or hypoblast because they are clearly separated from endoderm in pigs and cattle (fig. 2c, d). The further fate of the nodalexpressing domain in amniotes is not known. According to Hayek [1931], parachordal cells give rise to hypochord, a transient organ involved in vasculogenesis [Cleaver et al., 2000; Eriksson and Lofberg, 2000]. However, lineage tracing in Xenopus showed that the superficial mesoderm derived from the gastrocoel roof plate consists of 3 domains: the central domain becomes a part of the notochord, an intermediate domain gives rise to the hypochord, and the nodal-expressing lateral domains integrates into somites [Shook et al., 2004; Beyer et al., 2012]. Whether mammalian parachordal nodalexpressing cells contribute to paraxial somitic mesoderm or possess a functional homology to the hypochord will have to be the subject of a lineage tracing study.

\section{Heterochrony and the LRO}

Starting on the basis of an initially symmetrical paraxial nodal mRNA domain, ciliary flow causes inhibition of the right-sided activity of the nodal protein by inducing asymmetry of cerl-2 at the start of somitogenesis [Marques et al., 2004; Oki et al., 2009; Takao et al., 2013], which is followed by maintenance of nodal asymmetry through SELI [Nakamura et al., 2006]. In contrast, the paramedian nodal mRNA domain in pigs and cattle is initially asymmetrical and occurs at the early notochord formation stage (stage 5). This early initial asymmetry already at the mRNA level appears to be a reliable result
Schröder/Tsikolia/Weizbauer/Hue/ Viebahn 
in view of the number of specimens examined (especially in the pig) and may thus indicate that ciliary flow may be dispensable in these species. However, the paramedian nodal expression in pigs and cattle is still reconcilable with the concept of the PNC representing the universal mammal LRO: as the temporal differences in the initiation of molecular asymmetry imply, the PNC may operate at different developmental stages and may indicate either an alternative mechanism of LR symmetry breaking or, more simply, heterochrony of morphological development, while the emergence of morphological and molecular events differs in an LR symmetry breaking process which may be conserved at the cellular level. Among possible signs of such a heterochrony are different speeds of development until stage 5 is reached (6-7 days from fertilization in mice and rabbit vs. 12-13 days in pigs and cattle) and the different speeds and degrees of subchordal mesoderm regression (see above). The anterior-to-posterior shift of the paramedian nodal domain relative to the LPM nodal domain in the pig may be a further sign of the lower speed of development compared to mice and rabbits, while in all species the implementation of nodal expression in the LPM occurs very rapidly in late stage 7 until early stage 8 . This shift is reminiscent of the regression of the chick node 'leaving the notochord in its wake' [Streit and Stern, 1999] and may indicate - together with the reduction of the primitive streak size during stages 5 and 6 [Heuser and Streeter, 1929] - the involvement of the asymmetrical node regression during notochord formation in the pig, similar to the situation seen in the chick. This is also supported by the notion that in the chick node regression may be involved in LR symmetry breaking by confining the origin of the notochord to the right node shoulder [Otto et al., 2014].

\section{Conclusion}

The divergent initiation of the paraxial nodal expression domain is in line with the divergence of hypothetical mechanisms of LR symmetry breaking based on differences in the complex morphology of the LRO and in asymmetrical cellular movements near the node [Gros et al., 2009; Blum et al, 2014]. Taking into account the temporal differences in the development of the axial mesoderm may now lead to the discovery of a universal early LR patterning mechanism in mammals. The present study thus leaves open the possibility of an evolutionarily conserved mechanism which could reconcile the presence and absence of notochordal cilia and a cilia-dependent flow as well and may be helpful in the search for a common denominator in molecular mechanisms which lead to the universal morphological patterning of the LR situs in mammals. Because mechanical processes within the cytoskeleton - with its chirality of actin flow [Naganathan et al., 2014] and PCP-related asymmetric arrangement of proteins [Taniguchi et al., 2011; Gonzalez-Morales et al., 2015] - have been shown to be involved in LR symmetry breaking in both vertebrates and invertebrates, we speculate that (Wnt-dependent) PCP signaling [Walentek et al., 2012] may indeed be found to be part of the enigmatic uniform LR symmetry breaking mechanism.

\section{Acknowledgments}

We thank Kirsten Falk-Stietenroth, Heike Faust, and Irmgard Weiss for their excellent and dedicated technical assistance, and Hans-Georg Sydow for unfailing help with graphics work, Anja Beckers for providing cDNA probes of mice, Erwin Tönges for his help in the provision of pig embryos, Séverine A. Degrelle for the bovine nodal probe, and Christophe Richard and the UCEA team on the INRA farm for bovine embryo collection.

\section{References}

Bancroft, M., R. Bellairs (1977) The development of the notochord in the chick embryo, studied by scanning and transmission electron $\mathrm{mi}-$ croscopy. J Embryol Exp Morphol 35: 383401.

Basu, B., M. Brueckner (2008) Cilia multifunctional organelles at the center of vertebrate left-right asymmetry. Curr Top Dev Biol 85: 151-74.

Bellomo, D., A. Lander, I. Harragan, N.A. Brown (1996) Cell proliferation in mammalian gastrulation: the ventral node and notochord are relatively quiescent. Dev Dyn 205: 471-85.
Beyer, T., M. Danilchik, T. Thumberger, P. Vick, M. Tisler, I. Schneider, S. Bogusch, P. Andre, B. Ulmer, P. Walentek, B. Niesler, M. Blum, A. Schweickert (2012) Serotonin signaling is required for Wnt-dependent GRP specification and leftward flow in Xenopus. Curr Biol 10: 33-39.

Blum, M., P. Andre, K. Muders, A. Schweickert, A. Fischer, E. Bitzer, S. Bogusch, T. Beyer, H.W. van Straaten, C. Viebahn (2007) Ciliation and gene expression distinguish between node and posterior notochord in the mammalian embryo. Differentiation 75: 133-46.
Blum, M., K. Feistel, T. Thumberger, A Schweickert (2014) The evolution and conservation of left-right patterning mechanisms. Development 141: 1603-1613.

Boskovski, M.T., S. Yuan, N.B. Pedersen, C.K. Goth, S. Makova, H. Clausen, M. Brueckner, M.K. Khokha (2013) The heterotaxy gene GALNT11 glycosylates Notch to orchestrate cilia type and laterality. Nature 504: 456-459.

Cambray, N., V. Wilson (2002) Axial progenitors with extensive potency are localised to the mouse chordoneural hinge. Development 129: 4855-4866. 
Cleaver, O., D.W. Seufert, P.A. Krieg (2000) Endoderm patterning by the notochord: development of the hypochord in Xenopus. Development 127: 869-879.

Collignon, J., I. Varlet, E.J. Robertson (1996) Relationship between asymmetric nodal expression and the direction of embryonic turning. Nature 381: 155-158.

Dathe, V., A. Gamel, J. Männer, B. Brand-Saberi, B. Christ (2002) Morphological left-right asymmetry of Hensen's node precedes the asymmetric expression of Shh and Fgf8 in the chick embryo. Anat Embryol (Berl) 205: 343354.

Eriksson, J., J. Lofberg (2000) Development of the hypochord and dorsal aorta in the zebrafish embryo (Danio rerio). J Morphol 244: 167176.

Essner, J.J., J.D. Amack, M.K. Nyholm, E.B. Harris, H.J. Yost (2005) Kupffer's vesicle is a ciliated organ of asymmetry in the zebrafish embryo that initiates left-right development of the brain, heart and gut. Development 132: 1247-1260.

Feistel, K., M. Blum (2006) Three types of cilia including a novel $9+4$ axoneme on the notochordal plate of the rabbit embryo. Dev Dyn 235: 3348-3358.

-González-Morales, N., C. Géminard, G. Lebreton, D. Cerezo, J.B. Coutelis, S. Noselli (2015) The atypical cadherin dachsous controls leftright-asymmetry in Drosophila. Dev Cell 33: 675-689.

Gros, J., K. Feistel, C. Viebahn, M. Blum, C.J. Tabin (2009) Cell movements at Hensen's node establish left/right asymmetric gene expression in the chick. Science 324: 941-944.

Haldiman, J.T., H.T. Gier (1981) Bovine notochord origin and development. Anat Histol Embryol 10: 1-14.

Hamburger, V., H.L. Hamilton (1951) A series of normal stages in the development of the chick embryo. J Morphol 88: 49-92.

Hassoun, R., B. Püschel, C. Viebahn (2009) Sox 17 expression patterns during gastrulation and early neurulation in the rabbit suggest two sources of endoderm formation. Cells Tissues Organs 191: 68-83.

Hayek, H. (1931) Darmdach, Chorda und Hypochorda, Bursa pharyngea und ähnliche Bildungen in der Reihe der Wirbeltiere. Z Gesamte Anat 94: 293-344.

Heuser, C.H., G.L. Streeter (1929) Early stages in the development pig embryos. Contr Embryol Carnegie Inst 20: 1-30.

-Jurand, A. (1974) Some aspects of the development of the notochord in mouse embryos. J Embryol Exp Morphol 32: 1-33.

Leigh, M.W., J.E. Pittman, J.L. Carson, T.W. Ferkol, S.D. Dell, S.D. Davis, M. Knowles, M.A. Zariwala (2009) Clinical and genetic aspects of primary ciliary dyskinesia/Kartagener syndrome. Genet Med 11: 473-487.

Levin, M., R.L. Johnson, C.D. Stern, M. Kuehn, C. Tabin (1995) A molecular pathway determining left-right asymmetry in chick embryogenesis. Cell 82: 803-814.
Lewis, SL., P.P. Tam (2006) Definitive endoderm of the mouse embryo: formation, cell fates, and morphogenetic function. Dev Dyn 235: 2315-2329.

Loges, N.T., H. Olbrich, L. Fenske, H. Mussaffi, J. Horvath, M. Fliegauf, H. Kuhl, G. Baktai, E. Peterffy, R. Chodhari, et al. (2008) DNAI2 mutations cause primary ciliary dyskinesia with defects in the outer dynein arm. Am J Hum Genet 83: 547-58.

Lowe, L.A., D.M. Supp, K. Sampath, T. Yokoyama, C.V. Wright, S.S. Potter, P. Overbeek, M.R. Kuehn (1996) Conserved left-right asymmetry of nodal expression and alterations in murine situs inversus. Nature 381: $158-161$.

Männer, J. (2001) Does an equivalent of the 'ventral node' exist in chick embryos? A scanning electron microscopic study. Anat Embryol (Berl) 203: 481-490.

Marques, S., A.C. Borges, A.C. Silva, S. Freitas, M. Cordenonsi, J.A. Belo (2004) The activity of the Nodal antagonist Cerl-2 in the mouse node is required for correct $\mathrm{L} / \mathrm{R}$ body axis. Genes Dev 18: 2342-2347.

Maruotti, J., M. Munoz, S.A. Degrelle, E. Gomez, C. Louet, D. Diez, P.H. de Longchamp, V. Brochard, I. Hue, J.N. Caamano, et al. (2012) Efficient derivation of bovine embryonic stem cells needs more than active core pluripotency factors. Mol Reprod Dev 79: 461-477.

McGrath, J., S. Somlo, S. Makova, X. Tian, M. Brueckner (2003) Two populations of node monocilia initiate left-right asymmetry in the mouse. Cell 114: 61-73.

Merveille, A.C., E.E. Davis, A. Becker-Heck, M. Legendre, I. Amirav, G. Bataille, J. Belmont, N. Beydon, F. Billen, A. Clement, et al. (2011) CCDC39 is required for assembly of inner dynein arms and the dynein regulatory complex and for normal ciliary motility in humans and dogs. Nat Genet 43: 72-78.

Naganathan, S.R., S. Fürthauer, M. Nishikawa, F. Jülicher, S.W. Grill (2014) Active torque generation by the actomyosin cell cortex drives left-right symmetry breaking. Elife 3: e04165.

Nakamura, T., N. Mine, E. Nakaguchi, A. Mochizuki, M. Yamamoto, K. Yashiro, C. Meno, H. Hamada (2006) Generation of robust leftright asymmetry in the mouse embryo requires a self-enhancement and lateral-inhibition system. Dev Cell 11: 495-450.

Nakamura, T., D. Saito, A. Kawasumi, K. Shinohara, Y. Asai, K. Takaoka, F. Dong, A. Takamatsu, J.A. Belo, A. Mochizuki, H. Hamada (2012) Fluid flow and interlinked feedback loops establish left-right asymmetric decay of Cerl2 mRNA. Nat Commun 3: 1322.

- Okada, Y., S. Nonaka, Y. Tanaka, Y. Saijoh, H. Hamada, N. Hirokawa (1999) Abnormal nodal flow precedes situs inversus in iv and inv mice. Moll Cell 4: 459-468.

Oki, S., K. Kitajima, S. Marques, J. Belo, T. Yokoyama, H. Hamada, C. Meno (2009) Reversal of left-right asymmetry induced by aberrant Nodal signaling in the node of mouse embryos. Development 136: 3917-3925.
Olbrich, H., K. Haffner, A. Kispert, A. Volkel, A. Volz, G. Sasmaz, R. Reinhardt, S. Hennig, H. Lehrach, N. Konietzko, et al. (2002) Mutations in DNAH5 cause primary ciliary dyskinesia and randomization of left-right asymmetry. Nat Genet 30: 143-144.

Otto, A., T. Pieper, C. Viebahn, N. Tsikolia (2014) Early left-right asymmetries during axial morphogenesis in the chick embryo. Genesis 52: 614-625.

Rebagliati, M.R., R. Toyama, C. Fricke, P. Haffter, I.B. Dawid (1998) Zebrafish nodal-related genes are implicated in axial patterning and establishing left-right asymmetry. Dev Biol 199: 261-272.

Richard, C., I. Hue, V. Gelin, A. Neveux, E. Campion, S.A. Degrelle, Y. Heyman, P. ChavattePalmer (2014) Transcervical collection of bovine embryos up to Day 21: an 8-year overview. Theriogenology 15: 1101-1109.

Schwartz, P., H.M. Piper, R. Spahr, P.G. Spieckermann (1984) Ultrastructure of cultured adult myocardial cells during anoxia and reoxygenation. Am J Pathol 115: 349-361.

-Schweickert, A., P. Vick, M. Getwan, T. Weber, I. Schneider, M. Eberhardt, T. Beyer, A. Pachur, M. Blum (2010) The nodal inhibitor Coco is a critical target of leftward flow in Xenopus. Curr Biol 20: 738-743.

Schweickert, A., T. Weber, T. Beyer, P. Vick, S. Bogusch, K. Feistel, M. Blum (2007) Ciliadriven leftward flow determines laterality in Xenopus. Curr Biol 17: 60-66.

-Shiratori, H., H. Hamada (2006) The left-right axis in the mouse: from origin to morphology. Development 133: 2095-2104.

Shook, D.R., C. Majer, R. Keller (2004) Pattern and morphogenesis of presumptive superficial mesoderm in two closely related species, Xenopus laevis and Xenopus tropicalis. Dev Biol 270: 163-185.

-Smith, J.L., G.C. Schoenwolf (1989) Notochordal induction of cell wedging in the chick neural plate and its role in neural tube formation. J Exp Zool 250: 49-62.

-Song, H., J. Hu, W. Chen, G. Elliot, P. Andre, B. Gao, Y. Yang (2010) Planar cell polarity breaks bilateral symmetry by controlling ciliary positioning. Nature $466: 378-382$.

Stern, C.D. (2004) Gastrulation in the chick; in Stern, C.D. (ed): Gastrulation: from Cells to Embryo. New York, Cold Spring Harbor.

-Streit, A., C.D. Stern (1999) Mesoderm patterning and somite formation during node regression: differential effects of chordin and noggin. Mech Dev 85: 85-96.

Stubbs, JL., I. Oishi, J.C. Izpisúa Belmonte, C. Kintner (2008) The forkhead protein Foxj1 specifies node-like cilia in Xenopus and zebrafish embryos. Nat Genet 40: 1454-1460.

Sulik, K., D.B. Dehart, T. Iangaki, J.L. Carson, T. Vrablic, K. Gesteland, G.C. Schoenwolf (1994) Morphogenesis of the murine node and notochordal plate. Dev Dyn 201: 260-278. 
Takao, D., T. Nemoto, T. Abe, H. Kiyonari, H. Kajiura-Kobayashi, H. Shiratori, S. Nonaka (2013) Asymmetric distribution of dynamic calcium signals in the node of mouse embryo during left-right axis formation. Dev Biol 376: 23-30.

Taniguchi, K., R. Maeda, T. Ando, T. Okumura, N. Nakazawa, R. Hatori, M. Nakamura, S. Hozumi, H. Fujiwara, K. Matsuno (2011) Chirality in planar cell shape contributes to leftright asymmetric epithelial morphogenesis. Science 333: 339-341.

Theiler, K. (1972) The House Mouse: Atlas of Embryonic Development. Berlin, Springer.
Tsikolia, N., S. Schroder, P. Schwartz, C. Viebahn (2012) Paraxial left-sided nodal expression and the start of left-right patterning in the early chick embryo. Differentiation 84: 380-391.

Walentek, P., T. Beyer, T. Thumberger, A. Schweickert, M. Blum (2012) ATP4a is required for Wnt-dependent Foxj1 expression and leftward flow in Xenopus left-right development. Cell Rep 1: 516-527

Weisheit, G., D. Mertz, K. Schilling, C. Viebahn (2002) An efficient in situ hybridization protocol for multiple tissue sections and probes on miniaturized slides. Dev Genes Evol 212: 403-406.
Yoshiba, S., H. Shiratori, I.Y. Kuo, A. Kawasumi, K. Shinohara, S. Nonaka, Y. Asai, G. Sasaki, J.A. Belo, H. Sasaki, J. Nakai, B. Dworniczak, B.E. Ehrlich, P. Pennekamp, H. Hamada (2012) Cilia at the node of mouse embryos sense fluid flow for left-right determination via PKD2. Science 338: 226-231.

Zhou, X., H. Sasaki, L. Lowe, B.L. Hogan, M.R. Kuehn (1993) Nodal is a novel TGF-beta-like gene expressed in the mouse node during gastrulation. Nature 361: 543-547. 